\title{
COMPARISON OF TRANSVAGINAL ULTRASONOGRAPHY AND HYSTEROSCOPY IN THE EVALUATION OF PERI AND POSTMENOPAUSAL BLEEDING
}

\author{
Pratibha Garg1, Suman Yadav²
}

${ }^{1}$ Assistant Professor, Department of Obstetrics and Gynaecology, Gajra Raja Medical College and K.R. Hospital, Gwalior. ${ }^{2}$ Consultant, Department of Obstetrics and Gynaecology, Batra Hospital and Research Institute, New Delhi.

\section{ABSTRACT}

Anything that can significantly improve the accuracy of diagnosis, the cause of abnormal uterine bleeding in peri-menopausal and postmenopausal women can reduce the frequency of hysterectomy as a cure.

Abnormal uterine bleeding has become more important on 2nd half of twentieth century, because women are experiencing more menstrual cycles during their reproductive life.

AIM

To evaluate intrauterine abnormalities in symptomatic peri and postmenopausal bleeding by transvaginal ultrasonography and hysteroscopy.

\section{METHOD}

This prospective study was carried out on 60 patients with peri and postmenopausal bleeding attending Gynaecology OPD at Batra Hospital.

\section{RESULT}

Hysteroscopy has higher sensitivity for diagnosing endometrial abnormalities compared to TVS.

\section{KEYWORDS}

Abnormal Uterine Bleeding, TVS- Transvaginal Sonography, Hysteroscopy.

HOW TO CITE THIS ARTICLE: Garg P, Yadav S. Comparison of transvaginal ultrasonography and hysteroscopy in the evaluation of peri and postmenopausal bleeding. J. Evolution Med. Dent. Sci. 2016;5(21):1133-1136, DOI: 10.14260/jemds/2016/263

\section{INTRODUCTION}

The age of onset of menopause is 40 to 55 years and varies in different races. In India, it occurs between 44 to 50 years. ${ }^{1,2,3}$ Prior to menopause comes the perimenopausal transitional years that encompass the change from normal ovulation cycles to cessation of menses and are marked by irregularity of menstrual cycles.

Even without irregular bleeding or amenorrhoea, if a woman over the age of 52 years continues to menstruate she needs investigations to rule out endometrial hyperplasia and malignancy of genital tract. Other causes include fibroids, polyps, carcinoma endocervix and atrophic vaginitis.

Traditionally, dilatation and curettage used to be mainstay of investigation of abnormal uterine bleeding, but it is not accurate for diagnosing focal intrauterine lesions which are small or located in areas difficult to curette.

The present study aims to evaluate the different diagnostic methods, i.e. hysteroscopy which provides an optimal safe and cost effective strategy in modern management of women with peri and postmenopausal bleeding.

\section{MATERIAL AND METHOD}

The study was a prospective study conducted in the Department of Obstetrics and Gynaecology in Batra Hospital and Medical Research Centre, New Delhi, from March 2008 to November 2009.

Financial or Other, Competing Interest: None.

Submission 16-02-2016, Peer Review 29-02-2016,

Acceptance 03-03-2016, Published 14-03-2016.

Corresponding Author:

Dr. Pratibha Garg,

Department of Obstetrics and Gynaecology,

Batra Hospital and Research Institute,

New Delhi.

E-mail: prati_praveen@rediffmail.com

DOI: $10.14260 /$ jemds/2016/263
60 patients with peri and postmenopausal bleeding attending OPD were included in this study.

\section{Inclusion Criteria}

1. Perimenopausal women age $>40$ years with menorrhagia, menometrorrhagia, metrorrhagia, polymenorrhea, intermenstrual bleeding, post coital bleeding.

2. Postmenopausal bleeding after one year of amenorrhea.

3. Patient on hormone replacement therapy.

\section{Exclusion Criteria}

1. Age $<40$.

2. Pregnancy.

3. Patient with bleeding diathesis.

\section{METHOD}

Detailed history of patient was taken which included presenting complaints, history of presenting illness, menstrual history, obstetric history, family, past and personal history followed by a complete general physical examination including pulse rates, blood pressure and temperature. Systemic examination done to rule out any medical disorder. Pelvic examination done. Laboratory investigation whenever indicated was done like pregnancy test in perimenopausal woman, CBC, BT/CT, Pap smear.

After that the patient of abnormal uterine bleeding was subject to transvaginal ultrasound (Voluson Pro 730; GE Medical System) with a transvaginal probe of acoustic frequency of $10 \mathrm{MHz}$. Parameters studied included endometrial thickness, polyp, fibroid, growth, adnexal pathology or uterine pathology.

After that same patient was taken up for hysteroscopy followed by curettage or hysteroscopy-guided Bx of polyp or growth. 
Hysteroscopy was performed, preferably in postmenstrual phase or post bleeding phase. All were performed using a standard $5 \mathrm{~mm}$ hysteroscope with a $30^{\circ}$ fore-oblique lens.

Procedure was performed under GA. Normal saline was used as distension media.

\section{METHOD}

Detailed history of patient was taken which included presenting complaints, history of presenting illness, menstrual history, obstetric history, family, past and personal history followed by a complete general physical examination including pulse rates, blood pressure and temperature. Systemic examination done to rule out any medical disorder. Pelvic examination done. Laboratory investigation whenever indicated was done like pregnancy test in perimenopausal women, CBC, BT/CT, Pap smear.

After that the patient of abnormal uterine bleeding was subject to transvaginal ultrasound (Voluson Pro 730; GE Medical System) with a transvaginal probe of acoustic frequency of $10 \mathrm{MHz}$. Parameters studied included endometrial thickness, polyp, fibroid, growth, adnexal pathology or uterine pathology.

After that same patient was taken up for hysteroscopy followed by curettage or hysteroscopy-guided Bx of polyp or growth.

Hysteroscopy was performed, preferably in postmenstrual phase or post bleeding phase. All were performed using a standard $5 \mathrm{~mm}$ hysteroscope with a $30^{\circ}$ fore-oblique lens.

Procedure was performed under GA. Normal saline was used as distension media.

\section{RESULTS}

In this study, majority of patients (75\%) were of perimenopausal age group.

Mean age in perimenopausal group was 43.11 years and mean age in postmenopausal group was 55.93 years. Table- 1

Menorrhagia (33.3\%) was the most common presenting complaint followed by postmenopausal bleeding (25\%), dysmenorrhea (13.3\%), menometrorrhagia (11.6\%), postcoital bleeding $(6.6 \%)$, intermenstrual bleeding $(6.6 \%)$ metrorrhagia (3.3\%), Table 2 .

24 patients were nulliparous, of which majority (79.6\%) had abnormal endometrial finding indicating nulliparity as an associated risk factor for AUB, Table 3.

Hypertension was present in $21.6 \%$ cases, out of which $61.5 \%$ had abnormal endometrial pathology; diabetes in $18.3 \%$, out of which $81.8 \%$ had abnormal endometrial pathology; obesity in $5 \%$ of which $66.6 \%$ had abnormal endometrial pathology.

So hypertension, diabetes mellitus and obesity were associated with abnormal endometrial pathology in our study, Table 4

TVS have sensitivity of $59.2 \%$, specificity as $81.8 \%$, positive predictive value of $72.7 \%$ and negative predictive value of $71.0 \%$. P value is .001 , which is statistically significant for diagnosing hyperplastic endometrium.

Hysteroscopy has sensitivity of $62.9 \%$, specificity of $45.4 \%$, positive predictive value of $48.5 \%$ and negative predictive value as $60 \%$, p value was . 571 which is statistically not significant. So in this study, TVS has a higher specificity for diagnosis of endometrial hyperplasia compared to hysteroscopy, Table 5.

TVS had sensitivity of $47.0 \%$, specificity of $76.7 \%$, positive predictive value of $44.4 \%$ and negative predictive value of $78.5 \%$ for diagnosing endometrial polyp. P value .07 , which was statistically not significant, Table 6 .

Hysteroscopy has sensitivity of $52.1 \%$, specificity of $81.0 \%$, positive predictive value of $63.1 \%$ and negative predictive value of $73.1 \%$ for diagnosing endometrial polyp. $\mathrm{P}$ value was.319, which was statistically not significant, Table 7 . So hysteroscopy has been found to be more sensitive and specific in diagnosing endometrial polyp compared to TVS

TVS has sensitivity of $33.3 \%$, specificity of $94.7 \%$, positive predictive value of $25 \%$ and negative predictive value of $96.4 \%$ for detecting submucosal fibroid. P value was .701, which was statistically not significant. Hysteroscopy detected submucosal fibroids in 3 cases, of which 1 was confirmed by histopathology. This gave sensitivity of $50 \%$, specificity of $94.82 \%$, positive predictive value of $25 \%$ and negative predictive value of $98.21 \%$ for detecting submucosal fibroids. $P$ value was .012, which was statistically not significant.

The sensitivity, specificity and negative predictive value of hysteroscopy in higher for diagnosing submucosal fibroids to TVS.

We had only one patient with abnormal endometrial growth and detected hysteroscopically. HPE had confirmed it to be carcinoma endometrium, Table 9 .

In this study sensitivity, specificity, positive predictive value and negative predictive value of hysteroscopy was $85.7 \%, 56.0 \%, 73.1 \%, 73.6 \%$ respectively for detecting endometrial abnormalities.

TVS gave sensitivity, specificity, positive predictive value and negative predictive value of $84.2 \%, 72.2 \%, 84.2 \%$ and $72.7 \%$ respectively for detecting endometrial abnormalities.

So, in our study hysteroscopy has higher sensitivity for detecting endometrial abnormalities. This correlates with the study done by Bruno Cacciatore et al. $^{4}$ and Jaiswar Shyam Pyari et al. ${ }^{5}$

\begin{tabular}{|c|c|c|}
\hline & No. of Patients & Percent \\
\hline Perimenopausal & 45 & $75 \%$ \\
\hline Postmenopausal & 15 & $25 \%$ \\
\hline Total & 60 & $100 \%$ \\
\hline \multicolumn{3}{|c|}{ Table 1: Age Wise Distribution of Patients } \\
\hline
\end{tabular}

\begin{tabular}{|c|c|c|}
\hline Complaints & No. of Patients & Percent \\
\hline Menorrhagia & 20 & $33.3 \%$ \\
\hline Metrorrhagia & 2 & $3.3 \%$ \\
\hline Menometrorrhagia & 7 & $11.7 \%$ \\
\hline Polymenorrhea & 8 & $13.3 \%$ \\
\hline Intermenstrual bleeding & 5 & $8.3 \%$ \\
\hline Post-menopausal bleeding & 15 & $25 \%$ \\
\hline Postcoital bleeding & 3 & $5 \%$ \\
\hline Total & 60 & $100 \%$ \\
\hline
\end{tabular}

\begin{tabular}{|c|c|c|}
\hline Parity & No. of Patients & Percent \\
\hline Nulliparous (24) & $5(20.8 \%)$ & $19(79.1 \%)$ \\
\hline Multiparous (36) & $18(50 \%)$ & $18(50 \%)$ \\
\hline Total (60) & $\mathbf{2 3}$ & $\mathbf{3 7}$ \\
\hline \multicolumn{3}{|c|}{ Table 3: Parity in AUB } \\
\hline
\end{tabular}




\begin{tabular}{|c|c|c|c|c|}
\hline & Risk Factors & Postmenopausal Women & Perimenopausal Women & Total \\
\hline 1. & Hypertension & 7 & 6 & $13(21.6 \%)$ \\
\hline 2. & Diabetes mellitus & 4 & 7 & $11(18.3 \%)$ \\
\hline 3. & Hypothyroidism & 3 & 5 & $8(13.3 \%)$ \\
\hline 4. & Obesity & 0 & 2 & $3(5 \%)$ \\
\hline 5. & Breast cancer & 1 & 0 & $1(1.6 \%)$ \\
\hline 6. & Tamoxifen & 1 & 0 & $1(1.6 \%)$ \\
\hline 7. & OCPs* & 0 & 0 & $1(1.6 \%)$ \\
\hline 8. & HRT** & 0 & 0 & $0(0 \%)$ \\
\hline 9. & Smoking & 0 & 0 & $0(0 \%)$ \\
\hline 10. & Alcohol & 0 & & $0(0 \%)$ \\
\hline
\end{tabular}

*- Oral Contraceptives Pills, ** - Hormone Replacement

\begin{tabular}{|c|c|c|c|}
\hline \multirow{2}{*}{ Hysteroscopy } & \multicolumn{2}{|c|}{ HPR } & \multirow{2}{*}{ Total } \\
\cline { 2 - 3 } & Hyperplasia & Normal & \\
\hline Hyperplasia & 17 & 18 & 35 \\
\hline Normal & 10 & 15 & 25 \\
\hline Total & $\mathbf{2 7}$ & $\mathbf{3 3}$ & $\mathbf{6 0}$ \\
\hline Table 5: Comparison of Hysteroscopic \\
Endometrial appearance results with HPR \\
\hline
\end{tabular}

\begin{tabular}{|c|c|c|c|}
\hline \multirow{2}{*}{ TVS Polyp } & \multicolumn{2}{|c|}{ HPR Polyp. } & \multirow{2}{*}{ Total } \\
\hline & Yes & No & \\
\hline Yes & 8 & 10 & 18 \\
\hline No & 9 & 33 & 42 \\
\hline Total & 17 & 43 & 60 \\
\hline
\end{tabular}

*TVS- Transvaginal ultrasonography, **HPRHistopathological report.

\begin{tabular}{|c|c|c|c|}
\hline \multirow{2}{*}{ Hysteroscopy Polyp } & \multicolumn{2}{|c|}{ HPR Polyp } & \multirow{2}{*}{ Total } \\
\cline { 2 - 3 } & Yes & No & \\
\hline Yes & 12 & 7 & 19 \\
\hline No & 10 & 31 & 41 \\
\hline Total & $\mathbf{2 2}$ & $\mathbf{3 8}$ & $\mathbf{6 0}$ \\
\hline $\begin{array}{c}\text { Table 7: Incidence of Endometrial Polyps } \\
\text { findings on Hysteroscopy and HPR* }\end{array}$ \\
\hline
\end{tabular}

*HPR-Histopathological report.

\begin{tabular}{|c|c|c|c|}
\hline \multirow{2}{*}{ TVS Growth } & \multicolumn{2}{|c|}{$\begin{array}{c}\text { HPR Carcinoma } \\
\text { Endometrium }\end{array}$} & \multirow{2}{*}{ Total } \\
\cline { 2 - 3 } & Yes & No & \\
\hline Yes & 1 & 0 & 1 \\
\hline No & 0 & 59 & 59 \\
\hline Total & $\mathbf{1}$ & $\mathbf{5 9}$ & $\mathbf{6 0}$ \\
\hline \multicolumn{2}{|c|}{ Table 8: Incidence of Abnormal Endometrial } \\
Growth on TVS and HPR $^{* *}$ \\
\hline
\end{tabular}

*TVS- Transvaginal ultrasonography, **HPRHistopathological report.

\section{DISCUSSION}

In our study, majority of patients were of perimenopausal age group. This corresponds to studies done by Wyon et al. ${ }^{1}$ Randhawa et al. ${ }^{2}$ Kaw et al. ${ }^{3}$ In this study, menorrhagia was the most common presenting complaint followed by postmenopausal bleeding. A study by Jaiswar Shayam Pyari, et al. [2006]. ${ }^{5}$ had menorrhagia [40\%] as the most common symptom. We found that nulliparity as an associated risk factor for abnormal uterine bleeding. This correlates with the studies done by C. Farquhar et al. ${ }^{6}$ Sarah Feldman M.D. et al. ${ }^{7}$ Meira Epplein et al. ${ }^{8}$ in which nulliparity has been seen as an associated risk factor for endometrial hyperplasia/endometrial cancer. As per our study hypertension, diabetes mellitus and obesity were associated with abnormal endometrial pathology in our study. Similar results were seen in studies done by Sarah Feldman M.D. et al. ${ }^{7}$ and C. Farquhar et al. ${ }^{6}$ TVS compared to hysteroscopy has a higher specificity for diagnosis of endometrial hyperplasias. This correlates with the studies done by Mukhopadhayay S et al. ${ }^{9}$ Paraskevaidis E et al. ${ }^{10}$ and Chatpavit Getpook et al.11 In our study, hysteroscopy has been found to be more sensitive and specific in diagnosing endometrial polyps compared to TVS.

This corroborates with studies done by Bruno Cacciatore et al. and Mukhopadhayay S et al. ${ }^{9}$ Of 60 cases, TVS detected abnormal endometrial growth in one patient which was confirmed by histopathology. Hysteroscopy detected abnormal endometrial growth in one patient, which was confirmed by histopathology. This gave sensitivity of $100 \%$, specificity of $100 \%$, positive predictive value of $100 \%$ and negative predictive value of $100 \%$ in diagnosing endometrial cancer. This correlates with the study done by Rita Souse et al.12 Haller $\mathrm{H}$ et al.13 and Pekka Taipale et al.14 Since we had only one case of which was found to have cancer endometrium, much statistical importance cannot be given to this.

\section{CONCLUSION}

TVS is a simple, non-invasive and higher acceptable technique to the patient. It can identify women with perimenopausal and postmenopausal bleeding in which the likelihood of endometrial pathology is high and in whom tissue sampling should be performed.

Abnormal uterine bleeding is a symptom and not a disease. It is a common problem of perimenopausal or postmenopausal women. ${ }^{15}$

A recent meta-analysis found that in postmenopausal women a transvaginal sonography result of $5 \mathrm{~mm}$ or less endometrial thickness reduced the risk of disease by $84 \%{ }^{16}$ but some pathology may be missed by it. So it is recommended that hysteroscopy and biopsy should be performed if clinical suspicion is high. ${ }^{17,18}$

So we concluded that TVS should be used as routine first step diagnostic technique, but it may miss some small lesions like polyps, so hysteroscopy followed by histopathology should be considered as a standard modality to evaluation of abnormal uterine bleeding in perimenopausal and postmenopausal bleeding. 


\section{REFERENCES}

1. Singh A, Kaur S, Walia I. A historical perspective on menopause and menopausal age. Bull Indian Inst Hist Med Hyderabad 2002;32(2):121-35.

2. Randhwa I. Median age of menopause in a sample of Indian women. I J Pub-Health 1989;31-40.

3. Kaw D. Factors influencing the age at natural menopause. J Obstet Gynaecol India 1994;44:273-7.

4. Cacciatore B, Ramsoy T, Lehtoirta P, et al. Transvaginal ultrasonography versus hysteroscopy in postmenopausal bleeding. Acta Obstet Gynaecol Scand 1994;73:413-416.

5. Jaiswar Shyam Pyari, Sachan Rekha, Srivastava PK. A comparative diagnostic evaluation of hysteroscopy, transvaginal ultrasonography and histopathological examination in cases of abnormal uterine bleeding. Jobstet Gynecol India 2006;56(3):240-243.

6. Farquhar C, Lethaby A, Sowter M, et al. An evaluation of risk factors for endometrial hyperplasia in premenopausal women with abnormal menstrual bleeding. American Journal of Obstetrics and Gynaecology 1999;181(3):525-529.

7. Sarah Feldman, Francis Cook E, Bernard L Harlow, et al. Predicting endometrial cancer among older women who present with abnormal vaginal bleeding. Gynaecologic Oncology 1995;56(3):376-381.

8. Meira Epplein, Susan D Reed, Lynda F Voigt. Risk of complex and atypical endometrial hyperplasia in relation to anthropometric measures and reproductive history. American Journal of Epidemiology 2008;168(6):563-570.

9. Mukhopadhyay S, Bhattacharya SK, Ganguly RP, et al. Comparative evaluation of perimenopausal abnormal uterine bleeding by transvaginal sonography, hysteroscopy and endometrial biopsy. J Indian Med Assoc 2007;105(11):624, 626, 628 passim.

10. Parakevaidis E, Kalantaridou SN, Papadimitriou D. Transvaginal uterine ultrasonography compared with endometrial biopsy for the detection of endometrial disease in perimenopausal women with uterine bleeding. J Anticancer research ISSN 0250-7005, 2002;22(3):1829-1832.
11. Chatpavit Getpook, Saranya Wattanakumtornkul. To assess the role of measuring endometrial thickness by transvaginal ultrasonography (TVS) as a screening tool for abnormal uterine bleeding triage in premenopausal women. The Journal of Obstetrics and Gynaecology Research 2006;32(6):588-592.

12. Sousa R, Silvestre M, Almeida E, et al. Transvaginal ultrasonography and hysteroscopy in postmenopausal bleeding: a prospective study. Acta Obstet Gynaecol Scand 2001;80(9):856-62.

13. Haller $H$, Matecjcic N, Rukavina B, et al. Transvaginal sonography and hysteroscopy in women with postmenopausal bleeding. Int J Gynaecol Obstet 1996;54(2):155-9.

14. Pekka Taipale, Heikki Tarjanne, Ulla-Marja Heinonen. The diagnostic value of transvaginal sonography in the diagnosis of endometrial malignancy in women with peri- and postmenopausal bleeding. Acta Obstetricia et Gynecologica Scsandinavica 1994;73(10):819-823.

15. Bree RL, Bowerman RA, Bohm-Velez M, et al. US evaluation of the uterus in patients with postmenopausal bleeding: a positive effect on diagnostic decision making. Radiology 2000;216:260-264.

16. Nitze M. Uebr einenene behandlung method de hohien des menslichen korpes. Med Press Wein 1897;26:851.

17. Litta P, Merlin F, Saccardi C. Role of hysteroscopy with endometrial biopsy to rule out endometrial cancer in postmenopausal women with abnormal uterine bleeding. Maturitas 2005;50(2):117-23.

18. Garuti G, Sambruni I, Cellani F, et al. Hysteroscopy and transvaginal ultrasonography in postmenopausal women with uterine bleeding. Int J Gynaecol Obstet 1999;65(1):25-33. 